\title{
Beneficial Importance of Protein-rich Diets in the Management of Type 2 Diabetes: Need for a New Look.
}

\author{
Perez Quartey* \\ Faculty of Heath Sciences, Garden City University College, Ghana \\ *Corresponding author: Perez Quartey, Faculty of Heath Sciences, Garden City University College, Kenyase, Ghana. \\ To Cite This Article: Perez Quartey, Beneficial Importance of Protein-rich Diets in the Management of Type 2 Diabetes: Need for a New Look. Am J \\ Biomed Sci \& Res. 2019 - 6(4). AJBSR.MS.ID.001046. DOI: 10.34297/AJBSR.2019.06.001046.
}

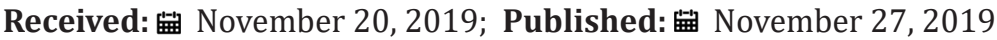

\section{Introduction}

The primary underlying mechanism of the development of type 2 diabetes is peripheral tissues' resistance to the metabolic actions of insulin, with obesity as a major contributor. Of importance is liver insulin resistance which provokes uncontrollable, ongoing gluconeogenesis as primary contributor of the systemic hyperglycinemia characterized with type 2 diabetes [1]. A secondary contributor is the defective glucose uptake by the skeletal muscles and adipose tissue. The combination of these two factors underlie the pathophysiology of the condition.

\section{Presentation}

Conventional dietary management of type 2 diabetes have focused on low intake of calorie-rich (carbohydrates and fats) diets, moderate protein intake and increased intake of fibre-rich diets [2]. The potential beneficial importance of protein-rich diets has not been given a major attention. This opinion piece focuses on addressing the potential benefits of protein-rich diets as a means of management of type 2 diabetes. A review by the American Diabetes Association [3] reported that there is inconclusive evidence of the beneficial importance of the concept of intake of low glycemic index/load foods on glycemic control in diabetes. However, the review showed that weight reduction is significantly associated with low risk of development of type 2 diabetes and better glycemic control.

\section{Hypothesis}

Since persistent hyperglycemia itself results from unbridled ongoing gluconeogenesis from liver insulin resistance, it appears metabolically prudent that the type 2 'diabetic system' does not need any further glycemic exposure from an exogenous source (diet). Afterall, the system is already challenged with the sustained hyperglycemia from inability to control ongoing gluconeogenesis. The primary source of precursors for gluconeogenesis are amino acids. The foregoing raises an intriguing question: If the metabolic system requires mobilized amino acids from the body's proteins for gluconeogenesis, why not give the gluconeogenic pathway its main precursors from protein-rich diets to limit the body's protein degradation as a means of extraction of glucogenic amino acid precursors for gluconeogenesis?

Additionally, protein-rich diets improve satiety with less food and reduce craving for food [4]. This means that whiles providing minimal calories and necessary gluconeogenic precursors, they also reduce the psychogenic need for additional glycemic exposure from the diet. The metabolic implication of the combination of intake of protein-rich diet that floods the gluconeogenic pathway with exogenous glucogenic amino acid precursors and reduction in food craving in the face of adipose tissue insulin resistance is that, the brunt of extra energy demand will shift to mobilization of fatty acids from adipose tissue stores. Protein-rich diets also increase the metabolic rate [5]. The rise in metabolic rate together with the continuous extraction of fatty acids from the adipose stores will collectively lead to a form of endogenous calorie-burning with an overall effect in weight reduction.

The overall metabolic effects of protein-rich diets can be summarized as:

a. Provision of minimal calories with rich-gluconeogenic precursors;

b. Reduction in food craving whiles promoting endogenous weight-reduction mechanisms.

\section{Conclusion}

Protein-rich diet may be a better alternative in the dietary management of type 2 diabetes and needs to be investigated further

\section{References}

1. Taylor R (2012) Insulin Resistance and Type 2 Diabetes. Diabetes 61(4): 778-779. 
2. Barclay A, Gilbertson H, Marsh K, Smart C (2010) Dietary management in diabetes. Aust Fam Physician 39(8): 579-583.

3. Sheard NF, Clark NG, Brand-Miller JC, Franz MJ, Pi-Sunyer FX, et al. (2004) Dietary Carbohydrate (amount and type) in the Prevention and Management of Diabetes: A Statement by the American Diabetes Association. Diabetes care 27(9): 2266-2271.
4. Paddon-Jones D, Westeman E, Mattes RD, Wolfe RR, Astrup A, et al. (2008) Protein, weight management, and satiety. Am J Clin Nutr 87(5): 1558S-1561S.

5. Westerterp KR (2004) Diet induced thermogenesis. Nutr Metab (Lond) 1: 5 . 